\title{
The Application of Web-Based Distance Learning to the Instrument (Guitar) Education In Undergraduate Program: The Sample of Kastamonu University
}

\author{
Ajda Aylin Can ${ }^{1}$, Okan Yungul ${ }^{2}$ \\ ${ }^{1}$ Marmara University, Atatürk Faculty of Education Department of Fine Arts Music Education Program, İstanbul, \\ Turkey \\ ${ }^{2}$ Kastamonu University, Faculty of Education Department of Fine Arts Music Education Program, Kastamonu, Turkey \\ Correspondence: Ajda Aylin Can, Marmara University, Atatürk Faculty of Education Department of Fine Arts Music \\ Education Program, İstanbul, Turkey.
}

Received: March 13, 2018

doi:10.11114/jets.v6i10.3102

\begin{abstract}
The aim of this study is to test the applicability of distance learning instrument education in undergraduate programs of higher education institutions. It is intended that a web-based experimental study has been designed for guitar education as a part of instrument education and that designed study has been applied to the undergraduate students through distance learning. Guitar performance rating scale was used to collect data. Obtained data was analyzed by using Mann Whitney $U$ and Wilcoxon nonparametric tests which measure and evaluate the significance of the difference between two mean scores. Following the analysis, the results were interpreted.

According to the findings, it was concluded that the intended target behaviors were attained by the students who were taught by the conventional method and the students who were taught by the web-based distance education method at the same level and the web-based distance education has had the same effect on students' learning as the traditional instrument education practice. Suggestions in this context suggestions were also provided.
\end{abstract}

Keywords: music education, undergraduate education, instrument education, distance learning

\section{Introduction}

Today, education system evolves to adapt to the lifestyles of modern societies in the direction of innovations brought with the $21^{\text {st }}$ century and tries to provide individuals educational needs by creating the most appropriate conditions for them. In particular, the impact of technology on our lives has changed both individuals' expectation in terms of educational system and the construction and function of that educational system in time. Distance learning studies can be indicated as an example for these developments and changes in education system. Distance learning studies beginning in $18^{\text {th }}$ century through newspapers in order to meet the individuals' educational needs who could not benefit from education opportunities developed over time. Today, internet and computer technologies are effectively used and distance learning continues to be used as a method through which mutual communication can be provided synchronously and by which education practices can be realized at any place and time as education environment.

Web-based distance learning is among the most preferred distance learning type today. Web-based distance learning has three models which are synchronic, asynchronic and mixed. Web-based distance learning enhances the quality of education by providing rich education environment for students and teachers and many advantages for both professional and institutional usage. Kanlı (2009) points out "with the spread of web-based education, all institutions especially education institutions, have an opportunity to reduce high cost due to the education system. They can provide education regardless of the distance and number of students. Besides, they gain a chance to organize effective, sufficient and high-quality courses. Distance learning students can utilize from a good technologic background and an effective teacher-student interaction as it is in traditional method education. They also have a chance to graduate from an efficient and strong high standard curriculum which was supported by various media devices." Besides, it is agreed that a new era for education is on the way thanks to developing technology. It is predicted that web-based distance learning will replace with traditional method education in time (Karaaslan, 2008, p. 168). According to Rees (2002), the widespread 
availability of the internet-based resources that facilitate learners' getting information accelerates the learning methods that are not limited to time and space. Technology allows people to work collaboratively on initiatives that transcend time and space; teachers, researchers, and students can create communities that deliver the information from anywhere in the world, share experiences, and focus on projects or issues of mutual interest at any time.

Distance education system which is frequently used in higher education and postgraduate education is considered as an opportunity for individuals to benefit from professional education. In general, distance learning education system is applied to individuals who reside far away from residential area and cannot benefit from education opportunities for various reasons. Distance learning system not only satisfies those people's need but also serves various duties for higher education institutions. In particular, distance education is used as an alternative to carry out education and educational activities in higher education institutions which do not have enough classrooms or sufficient number of teaching staff.

It is thought that distance learning can also be used in music teaching area as it is used in different learning areas and different institutions. The troubles to find qualified instrument instructor to give individual instrument courses reveals the need for this method. Uslu (2013) has reported that the quality of the instrumental lectures could not be achieved at the desired level because of the lack of teaching staff in the institutions, the increase of the number of students, the taking of more than one student in one class hour. Kasap (2007), on the other hand, has stated that considering the limited number of the staff to provide music education in higher education institutions, distance learning can be useful to benefit from various music courses easily.

As a result of the scanning of the literature, various distance education activities have been realized in the field of music education.

Literature review resulted various distance learning studies in music education field in Turkey. First distance learning study in the field of music education was "violin education by letters" prepared by Edip Günay and Ali Uçan in Turkey in 1974-1975 education term. Due to the technical flaws, program received student only for one year and sending letters were waived just in the second year of the program (Canbay and Nacakç1, 2011, p 135-137).

The study of Sağer, Eden and Şallıel (2014) is intended to demonstrate that distance education can also be applied to music education and its sub-sections such as music community education and management. The research was conducted within the scope of concert preparations of Malatya Inonu University Chamber Orchestra and the conductor. Because the desired performance could not be achieved in the research, internet infrastructure and voice transmission, it was not possible to perform the concert with the conductor who connected with distance and the second orchestra conductor was needed where the orchestra was located. The conductor connected with distance took the responsibility of sharing the musical expressions with the second conductor and the orchestra.

In his study, Karahan (2016) aimed to determine the success levels of the students' achievement in traditional piano courses and in synchronous distance piano learning courses. As a result of the study using the experimental model, there was no significant difference in the performance of the piano playing between experiment group students who received synchronous distance piano learning courses and control group who received traditional piano courses. In addition, no significant difference was found between the levels of development of the piano playing performances of the experimental group and the control group students. These results indicate that synchronous distance piano learning courses developed students playing piano performances equally as traditional piano courses.

In the study of Kruse, Harlos, Callahan, and Herring (2013), piano lessons at graduate level was carried out through Skype application. Findings include information about the benefits, difficulties and feasibility of distance learning in the Skype piano lessons. In this direction, teachers and students were able to attend classes from various locations. Due to insufficient technological equipment used in these piano classes, some problems have been experienced and these problems have been solved by making some changes and arrangements. As the distance learning configurations can vary universally, the transferability of research findings to other studies is not always possible. It has been emphasized that Skype courses may become more traditional in colleges and universities, as the instructors become technologically more conscious and the potential of the technology becomes more public.

Higher education institutions which provide music education are the most important institutions for professional educational. Problems that might occur in those institutions can cause irreparable professional damages for people who receive music education. It is thought that lack of instructor in instrument education which is a fundamental stone for music education will cause students to feel insecure and experience self-confidence issues in their professional lives, especially when they present a performance with their instruments. Thus, they may even give unqualified instrument education due to the problems discussed before.

The problem situation of this study is to determine whether this lack of instructor problem in music institutions can be solved through distance learning education as an alternative method. 


\section{Purpose}

The aim of this study is to examine the applicability of distance learning in instrument education at undergraduate programs in higher education institutions. So, an experimental web-based research was designed for guitar education and applied by using distance learning.

\subsection{Hypothesis}

1. There is no significant difference between pre-test scores of guitar performance rating scale of the students who receive web-based distance learning and the students who receive traditional methods.

2. There is a significant difference between pre-test and post-test scores of guitar performance rating scale of the students who received traditional methods.

3. There is a significant difference between pre-test and post-test scores of guitar performance rating scale of the students who receive web based distance learning.

4. There is no significant difference between post-test scores of guitar performance rating scale of the students who receive web-based distance learning and the students who receive traditional methods.

\section{Method}

\subsection{Research Design}

In the study, real experimental design with pretest-posttest matched control group was applied within the scope of quantitative method. This pattern is used to increase the possibility of matching groups of subjects. Experimental pairs are formed on certain variables that are determined for that aim. Theories, researcher experiences, expert opinions or pretest scores can be used to construct subject pairs. The subjects in the pairs are randomly placed to experimental and control groups. Coding for this design can be done as follows (Büyüköztürk, Kılıç Çakmak, Akgün, Karadeniz ve Demirel, 2014, s.207).

\begin{tabular}{lllll}
\hline Experimental Group & $\mathrm{M}_{\mathrm{R}}$ & Pretest & Web Based Distance Learning & Posttest \\
Control Group & $\mathrm{M}_{\mathrm{R}}$ & Pretest & & Posttest
\end{tabular}

The collected data were analyzed and interpreted by the Mann Whitney $U$ test, which is the nonparametric test for the difference between the independent two group averages, and by the Wilcoxon test, which is the nonparametric test for the difference between the two dependent group averages.

\subsection{Study Group}

This research was carried out by a study group consisting of 6 students who were from Music Education Department of Fine Arts, Faculty of Education at Kastamonu University and the fall semester of 2017-2018 academic year.

The study group of the research is composed of 6 students (A1, A2, A3, A4, A5, A6) who take Individual Instrument (Guitar) I course in Music Education Department. In order to determine the level of the students in the study group, 3 works were determined at different levels and students were asked to study these musical works for 10 days. After 10 days, two students could decipher and play 1 work, two of them could decipher and play 2 works, and two of them could decipher and play 3 works. Two students playing 1 work took place in the $1^{\text {st }}$ level group, 2 students playing 2 works were in the $2^{\text {nd }}$ level group, and 2 students playing 3 works were in the $3^{\text {rd }}$ level group. Thus, 3 levels and 2 students in each level were identified.

The students' performances were recorded by a camera and presented to the assessment jury that is composed of 1 research assistant, 1 assistant professor doctor and researcher. As a result of Jury's performance scores, 2 students in each level were paired and assigned to experimental and control groups.

The group separation performance scores and levels of the students received from the assessment jury are shown in Table 1. 
Table 1. Group separation performance scores

\begin{tabular}{|c|c|c|c|c|c|c|c|c|}
\hline \multirow{2}{*}{\multicolumn{2}{|c|}{ Level Students }} & \multirow{2}{*}{ Musical Works } & \multirow{2}{*}{\multicolumn{3}{|c|}{$\begin{array}{ccc}\text { Evaluator Evaluator Evaluator } \\
1 & 2 & 3\end{array}$}} & \multirow{2}{*}{\multicolumn{3}{|c|}{ Total Mean Performance Score Mean }} \\
\hline & & & & & & & & \\
\hline \multirow[t]{2}{*}{1} & A1 & 1. Musical Work & 29 & 29 & 28 & 86 & 28,6 & 28,6 \\
\hline & $\mathrm{A} 2$ & 1. Musical Work & 27 & 27 & 26 & 80 & 26,6 & 26,6 \\
\hline \multirow[t]{4}{*}{2} & A3 & 1. Musical Work & 33 & 33 & 32 & 98 & 32,6 & 32,45 \\
\hline & & 2. Musical Work & 32 & 33 & 32 & 97 & 32,3 & \\
\hline & A4 & 1. Musical Work & 36 & 36 & 37 & 109 & 36,3 & 37,15 \\
\hline & & 2. Musical Work & 36 & 37 & 41 & 114 & 38 & \\
\hline \multirow[t]{6}{*}{3} & A5 & 1. Musical Work & 48 & 42 & 50 & 140 & 46,6 & 39,96 \\
\hline & & 2. Musical Work & 35 & 37 & 45 & 117 & 39 & \\
\hline & & 3. Musical Work & 30 & 36 & 37 & 103 & 34,3 & \\
\hline & A6 & 1. Musical Work & 45 & 44 & 51 & 140 & 46,6 & 40,3 \\
\hline & & 2. Musical Work & 34 & 37 & 38 & 109 & 36,3 & \\
\hline & & 3. Musical Work & 37 & 39 & 38 & 114 & 38 & \\
\hline
\end{tabular}

As shown in Table 1, A1 and A2 played one musical work and took place in the $1^{\text {st }}$ level group. A1 received mean score of 28,6 from the assessment jury while A2 received mean score of 26,6. A3 and A4 played two songs and took place in the $2^{\text {nd }}$ level group. A3 received mean score of 32,6 for the first song and 32,3 for the second song. Total performance mean score is 32,45 . A4 received mean score of 36,3 from the first song and 38 for the second song. Total performance mean score is 37,51. A5 and A6 played three songs for each. A5 received mean score of 46,6 for the first song, 39 for the second song and 34,3 for the third song. Total performance mean score is calculated as 39,96. However, A6 received mean score of 46,6 for the first song, 36,3 for the second song and 38 for the third song. Total performance mean score is 40,3.

Students were first matched according to their total performance score means and then separated as experiment and control groups as shown in Table 2.

Table 2. Experiment and Control Groups

\begin{tabular}{|c|c|c|c|}
\hline Experiment Group & $\begin{array}{l}\text { Total Performance } \\
\text { Mean Score }\end{array}$ & Control Group & $\begin{array}{c}\text { Total Performance } \\
\text { Mean Score }\end{array}$ \\
\hline A1 & 28,6 & $\mathrm{~A} 2$ & 26,6 \\
\hline A3 & 32,45 & A4 & 37,15 \\
\hline A5 & 39,96 & A6 & 40,3 \\
\hline $\begin{array}{l}\text { Group } \\
\text { Mean Score }\end{array}$ & 33,6 & $\begin{array}{l}\text { Group } \\
\text { Mean Score }\end{array}$ & 34,68 \\
\hline
\end{tabular}

As presented in Table 2, students were matched as A1 $(28.6)$ with A2 $(26,6)$, A3 $(32,45)$ with A4 $(37,15)$ and A5 $(38,96)$ with A6 $(40,3)$ according to their total performance score means. To form groups, it is paid attention that mean scores for group pairs are close. As a result, experiment group mean score was 33,6 and control group mean score was 34,68. Two equal groups were formed.

\subsection{Study Process}

Guitar education applied for this study was carried out by the researcher and applied to the study group for 8 weeks. Before the applications, web based distance learning classroom were arranged and designed both in Marmara University Distance Learning Application and Research Center (UZEM) and Kastamonu University Education Faculty Department of Fine Arts Music Education programs. Internet, hardware, software and multimedia devices were set ready in the computer that teachers and students would use. Besides, television screen, computers, guitars, speakers, printer, camera etc. were provided and tested before the application.

Hardware used to accomplish distance guitar learning were presented below.

\section{Marmara University Distance Learning Classroom}

50 inch 127 Screen Full HD LED Television

Laptop computer

Web Cam (HD)

Condenser Studio Microphone

Soundbar audio system

External Sound Card

Kastamonu University Distance Learning Classroom 


\section{9 inch 124 Screen Full HD LED Television}

\section{Laptop Computer}

Web Cam (HD)

Condenser Studio Microphone

Soundbar audio system

External Sound Card

Printer

Skype $^{\mathrm{TM}}$ was used in this study to provide both vocal and visual connection with the students. To share the necessary documents for the course with the students, screen sharing feature of "perculus" application that is integrated to the Learning Management System (LMS) in UZEM was used. "Guitar Education" course was constructed on LMS for experiment group courses. User pages were prepared so students log in with their user names and passwords and enter virtual courses.

Curriculum for 'Individual Instrument (Guitar) Course' in Marmara University Education Faculty Department of Fine Arts Education, Music Education Program was investigated and course contents of Individual Instrument (Guitar) I for the first level students, Individual Instruments (Guitar) II for the second level students and Individual Instrument (Guitar) III for the third level students were constructed considering the objectives of 8-week education term. Documents to be used in the study were added to LMS.

All stages and preparations for experiment study was again revised and application process was started.

\subsection{Application Process}

Before application process, students were asked to study for a given musical works which were suitable for their level and requested to study for 1 week. At the end of a week, students' performances were measured with guitar performance rating scale and their pre-test scores were obtained.

Experiment group students were asked to determine their user names and passwords to log in LMS and each student was identified to their user pages. Information about how to use Students LMS, video and voice call on Skype ${ }^{\mathrm{TM}}$ and use of document sharing screen was provided to experiment group students and control for distance learning system start, logging in the system, setting course screen up etc. were left to students.

In the application process, course content was shared with experiment group via web-based distance learning with different places, synchronically and using video conference method and one to one while control group received traditional method, in the same place, one to one. Each student had a class of 50 minutes long each week during the 8 -week period.

The course documents were provided to the control group during the course while experiment group took the same material via LMS.

At the end of the application, students' performances were measured by guitar performance rating scale and their post-test scores were obtained.

\subsection{Data Collection Tools}

Guitar performance rating scale was used as data collection tool.

Guitar performance rating scale which was developed by Akçay (2011) to determine students' performance objectively in Individual Instrument (Guitar) Courses in Music Departments of Fine Arts Faculties and Music Education Programs of Education Faculties was arranged according to nine experts' oral and written opinions and suggestions. Experts points out that it can be used to measure guitar performance.

The generated scale was applied to 7 students of individual instrument guitar course and 4 persons from teaching staff participated in the research as a scorer. The scope, format, Likert and scoring method of the scale are clearly understood by all the teaching staff. 15 items collected under 3 dimensions on the scale is able to be scored in a time that is convenient to the use of the measuring instrument during performance.

While the measurement tool consisted of 30 items, the scale was reduced to 15 items considering expert opinions.

Principal component analysis revealed a one-dimensional structure; that's, the scale measures one basic feature. Factor loadings were observed to change between .65 and .86 . To determine the reliability of the scale, internal consistency reliability (Cronbach's alpha) and inter-rater reliability (Kendal's W) were performed. Analysis results showed that Cronbach's alpha coefficients of all items but fifth change between .81 and .86. Cronbach's alpha coefficient for overall 
scale was .84 . It can be concluded with this finding that the guitar performance rating scale has acceptable internal reliability. Kendall's W inter-rater reliability was .60. In summary, reliability coefficient was determined above .80 . The factor loadings of items were observed between validity between .65 and .86 . Therefore, the measurement tool was decided to be reliable and valid to be used within the scope of this study.

\section{Findings and Comments}

In this section, findings which were achieved as a result of the analysis and interpretations based on these findings were presented.

1- Findings of the hypothesis, "There is no significant difference between pre-test scores of guitar performance rating scale of the students who receive web-based distance learning and the students who receive traditional methods", were presented in Table 3.

Table 3. Mann Whitney U test results which was conducted to determine the difference between guitar performance rating scale of students received traditional education and students received web based distance learning

\begin{tabular}{llllllll}
\hline Score & Groups & $N$ & Mean Rank & Rank Sum & $U$ & $z$ & $p$ \\
\hline \multirow{4}{*}{ Guitar Performance Rating Scale Pre-test } & Control & 3 & 3,67 & 11,00 & & & \\
& Experiment & 3 & 3,33 & 10,00 & 4,000 & $-0,218$ & 0,827 \\
& Total & 6 & & & & & \\
\hline
\end{tabular}

As shown in Table 3, there was no significant statistical difference ( $p>0.05)$ between pre-test scores of guitar performance rating scale of the students who receive web-based distance learning and the students who receive traditional methods.

As a result of this finding, it can be proved that students were separated in two equal groups by means of their performances. So, experimental study was started with two equal groups.

2- Findings of the hypothesis, "There is a significant difference between pre-test and post-test scores of guitar performance rating scale of the students who received traditional methods", were presented in Table 4.

Table 4. Wilcoxon Signed Rank Test which was conducted to determine the difference between pre and post-test scores obtained by guitar performance rating scale of students who received traditional method education

\begin{tabular}{lllllll}
\hline Score & Rows & $N$ & Mean Rank & Rank Sum & $z$ & $p$ \\
\hline \multirow{3}{*}{$\begin{array}{l}\text { Performance Post-test } \\
\text { Performance Pre-test }\end{array}$} & 0 &, 00 &, 00 & & \\
& Positive & 3 & 2,00 & 6,00 & & \\
& Equal & 0 & & & & \\
& Total & 3 & & & & \\
\hline
\end{tabular}

As shown in Table 3, there was no significant statistical difference ( $p>0.05)$ between pre-test and post-test scores of guitar performance rating scale of the students who receive web-based distance learning and the students who receive traditional methods.

Pre and post-test scores obtained from the assessment jury members based on the performance rating scale for students received traditional method education were also presented in Table 4.1.

Table 4.1 Pre and Post-test Scores obtained by Guitar Performance Rating Scale of Students who received traditional method education

\begin{tabular}{|c|c|c|c|c|c|}
\hline Group & Students & Pre-test & Pre-test Mean & Post-test & Post-test Mean \\
\hline \multirow{3}{*}{$\begin{array}{l}\text { Co } \\
\text { ntrol }\end{array}$} & A2 & 23,33 & \multirow{3}{*}{35,22} & 43 & \multirow{3}{*}{50,44} \\
\hline & A4 & 32,33 & & 42 & \\
\hline & A6 & 50 & & 66,33 & \\
\hline
\end{tabular}

Table 4.1. showed that pre-test mean scores, obtained via guitar performance scale, of students who received traditional method education was 35,22; post-test mean score was 50,44. Based on this finding, it can be concluded that students made progress as a result of the education they were provided.

3- Findings of the hypothesis, "There is a significant difference between pre-test and post-test scores of guitar performance rating scale of the students who receive web based distance learning" were presented in Table 5.

Table 5. Wilcoxon Signed Rank Test Results which was conducted to determine the difference between pre and post-test scores obtained by guitar performance rating scale of students who received web based distance learning education

\begin{tabular}{lllllll}
\hline Score & Rows & $N$ & Mean Rank & Rank Sum & $z$ & $p$ \\
\hline \multirow{3}{*}{ Performance Post-test } & Negative & 0 &, 00 &, 00 & & \\
Performance Pre-test & Positive & 3 & 2,00 & 6,00 & & \\
& Equal & 0 & & & $-1,604$ & 0,109 \\
& Total & 3 & & & & \\
\hline
\end{tabular}


As shown in Table 5, there was no significant statistical difference ( $p>0.05$ ) between pre-test and post-test scores of guitar performance rating scale of the students who receive web-based distance learning.

Pre and post-test scores obtained from the assessment jury members based on the performance rating scale for students received web-based distance learning were also presented in Table 5.1.

Table 5.1. Pre and Post-test Scores obtained by Guitar Performance Rating Scale of Students who received web based distance learning education

\begin{tabular}{|c|c|c|c|c|c|}
\hline Group & $\begin{array}{l}\text { Stude } \\
\text { nts }\end{array}$ & Pre-test & Pre-test Mean & Post-test & Post-test Mean \\
\hline \multirow{3}{*}{ Experiment } & A1 & 29 & \multirow{3}{*}{31,44} & 54,33 & \\
\hline & A3 & 29,3 & & 54,33 & 57,44 \\
\hline & A5 & 36 & & 63,66 & \\
\hline
\end{tabular}

As presented in Table 5.1. pre-test mean scores, obtained via guitar performance scale, of students who received web based distance learning education was 31,44; post-test mean score was 57,44. Based on this finding, it can be concluded that students made progress as a result of the education they were provided.

4- Findings of the hypothesis, "There is no significant difference between post-test scores of guitar performance rating scale of the students who receive web-based distance learning and the students who receive traditional methods were presented in Table 6.

Table 6. Mann Whitney U Test Results which was conducted to determine the difference between post-test scores obtained via guitar performance rating scale of students who received web based distance learning education and traditional method education

\begin{tabular}{llclllll}
\hline Score & Groups & $N$ & Mean Rank & Rank Sum & $U$ & $z$ & $p$ \\
\hline \multirow{3}{*}{ Guitar Performance Rating Scale Post-test } & Control & 3 & 3,00 & 9,00 & & & \\
& Experiment & 3 & 4,00 & 12,00 & 3,000 & $-0,664$ & 0,507 \\
& Total & 6 & & & & &
\end{tabular}

As shown in Table 6, there was no significant statistical difference ( $p>0.05)$ between post-test scores of guitar performance rating scale of the students who receive web-based distance learning and of the students who receive traditional education.

As a result of this experimental study, students accomplished the objectives equally no matter if they receive traditional instrument education or web based distance learning. In other words, web-based distance instrument learning is as effective as traditional instrument teaching.

\section{Results and Recommendations}

\subsection{Results}

1) The findings revealed that there is no significant difference between mean scores of students' guitar performances, who received traditional education and web-based distant learning. It was concluded in this study that instrument education which was provided with two different methods had the same effects on students' guitar performances. The finding is very similar to that of Karahan (2016).

2) Instrument distance learning education was performed in three different performance groups in this study. Web-based distance learning education was proved to be efficient in all students' performance groups.

3) It was also concluded that music education institutions for undergraduate programs can also use web-based distance learning as an alternative education method to traditional instrument education.

\subsection{Recommendations}

1) Music training institutions which are in the need of instrument teachers at undergraduate level should be determined and distance education applications should be organized to address this need.

2) It can be suggested to conduct future researches to study whether distance learning can be applied to the other courses from the curriculum of music education teaching program at undergraduate programs beside instrument teaching course. Tecimer (2006) stated that most universities in the World provided distance learning programs for music education thanks to the opportunities of internet. These courses were reported to promote traditional education.

3) Researches concerning uses of asynchronous education model which is among distance learning types can also be investigated.

4) It is suggested to build distance learning education classrooms to carry out instrument courses in education institutions which provide instrument education at undergraduate level. 
5) Distance learning for instrument education are also advised for music education institutions at higher and undergraduate programs. Can and Yungul (2017) stated in their study that students in master programs can minimize the problems they face with the help of distance learning. Besides, Öztürk and Dinç (2016) suggest solutions to the problems of music teachers, who were also postgraduate students. The solution they suggested was to build coordination between universities and Ministry of National Education. So, teachers may attend distance learning postgraduate programs and avoid the problems they meet with traditional programs.

\section{References}

Akçay, Ş. Ö. (2011). A study of developing performance scale in guitar education (Unpublished Master Thesis), Atatürk University Institute of Education Sciences, Erzurum.

Büyüköztürk, Ş., Kılıç, Ç. E., Akgün, Ö. E., Karadeniz, Ş., \& Demirel, F. (2014). Bilimsel Araştırma Yöntemleri, Pegem Akademi, 18.Bask1, Ankara.

Can, A. A., \& Yungul, O. (2017). Determining the views of graduate students, who receive instrument education at music institute, towards distance education, The Journal of Academic Social Science, 5(45), 155-168. https://doi.org/10.16992/ASOS.12216

Canbay, A., \& Nacakçı, Z. (2011). Content analysis of application of teaching violin with letter, Mehmet Akif Ersoy University Journal of Education Faculty, 11(21), 134 -152.

Kanl, Ö. (2009). Evaluation of web-based distance education system developed with current technologies using a sample application (Unpublished Master Thesis), Beykent University Graduate School of Natural and Applied Sciences: İstanbul.

Karaaslan, A. İ. (2008). The effective web design model in distance learning and an application (Unpublished Doctoral Thesis), Dokuz Eylül University Institute of Social Sciences: İzmir.

Karahan, A. S. (2016). The evaluation of synchronic distance piano teaching in comparison with the traditional piano teaching, International Periodical for the Languages, Literature and History of Turkish or Turkic, Turkish Studies, 11(21), 211-228. https://doi.org/10.7827/TurkishStudies.11244

Kasap, T. B. (2007). Müzik Eğitiminde Teknolojik Yaklaşımlar, 38. Uluslararası Asya ve Kuzey Afrika Çalışmaları Kongresi, Cilt:1, Ankara, 447-454.

Kruse, N. B., Harlos, S. C., Callahan, R. M., \& Herring, M. L. (2013). Skype music lessons in the academy: Intersections of music education, applied music and technology. Journal of Music, Technology \& Education, 6(1), 43-60. https://doi.org/10.1386/jmte.6.1.43_1

Öztürk, G. F., \& Dinç, H. (2016). Music instructors who simultaneously receive postgraduate education: the problems that they face during their studies, Idil, 5(21). https://doi.org/10.7816/idil-05-21-15

Rees, F. (2002). Distance learning and collaboration in music education. In R. Colwell \& C. Richardson (Eds.), The new handbook of research on music teaching and learning (pp. 257-273). New York: Oxford.

Sağer, T., Eden, A., \& Şallıel, O. (2014). Distance learning in music education and orchestral applications, Inonu University Journal of Art and Design, 4(9), 69-79.

Tecimer, B. (2006). İnternet ve Yaşam Boyu Müzik Eğitimi, Müzed, 15, 8-9.

Uslu, M. (2013). Evaluation of the instructor views about conducting the individual instrumental (violin) training in the faculties of education, Journal of Research in Education and Teaching, 2(1), 47-57.

\section{Copyrights}

Copyright for this article is retained by the author(s), with first publication rights granted to the journal.

This is an open-access article distributed under the terms and conditions of the Creative Commons Attribution license which permits unrestricted use, distribution, and reproduction in any medium, provided the original work is properly cited. 